\title{
Ballistic tests and numerical simulations for containment capability characterisation of Waspaloy ${ }^{\circledR}$ alloy
}

\author{
M. Di Sciuva ${ }^{1}$, M. Degiovanni ${ }^{1}$, M. Mattone ${ }^{1}$, M. Gherlone $^{1}$, \\ N. Bonora ${ }^{2}$, A. Ruggiero ${ }^{2} \&$ C. Frola ${ }^{3}$ \\ ${ }^{1}$ Aerospace Engineering Department, Politecnico di Torino, Italy \\ ${ }^{2}$ Industrial Engineering Department, Università di Cassino, Italy \\ ${ }^{3}$ Engineering Advanced Technology, Avio S.p.A., Italy
}

\begin{abstract}
This article presents the results of an experimental and numerical activity for the characterisation of the containment capability of Waspaloy ${ }^{\circledR}$ alloy, used for the case in aircraft engines. The ballistic facility is described and the impact experiments outcomes are discussed; some preliminary numerical simulations are also briefly presented.
\end{abstract}

Keywords: blade containment, ballistic tests, airgun, Waspaloy, high strain rate, impact response.

\section{Introduction}

Turbine casings are the heaviest elements of an aircraft engine, thus the lightening of the containment case, without jeopardizing the structural integrity level, would lead to great advantages such as the reduction of the absolute weight of the whole engine and to an increase of the engine performance (specific thrust per unit weight), Kelvin [1].

In casing design, the minimum thickness allowed for the released blade containment requirements $[2,3]$ is usually determined via the use of experimental ballistic curves and, eventually, endorsed by blade out event FEM simulations [1, 4-7]. A possible work plan for casing containment design could be: (1) to obtain, through experiments, both the static and the dynamic characterisation of the material (in the strain rate range of interest), (2) to perform the ballistic tests 
on the specimens with which looking for the minimum containment thickness, (3) to validate the FEM model of the ballistic tests (using the material characterisation coming from step (1)) in order to simulate with an appropriate accuracy the experimental results, (4) to obtain, via a set of reliable FEM simulations, a containment curve to be used during the design process. While step (1) and (2) are mainly experimental in nature, steps (3) and (4) can be performed using a design-by-analysis approach based on extensive use of numerical simulations. Experimental testing is mandatory because of two main reasons, at least: (a) to characterize material behaviour at high strain rates and (b) to validate the numerical simulation framework. Also FEM simulations are required in order to describe a containment curve without recurring to experimental tests. Anyway, both the ballistic tests and the FEM simulations should be limited to a reasonable number: tests are very expensive both for the set up of the facility and for the cost of specimens, numerical calculations need much time for modelling and for the analysis. Thus, by means of response surface techniques based on a reduced number of tests/simulations, it is possible to describe the dependence of the containment thickness from the key parameters of the problem (kinetic energy of the projectile, material, etc.) $[4,8,9]$.

In this paper we present the ballistic tests conducted on some Waspaloy ${ }^{\circledR}$ alloy plates. The experimental set-up and results are presented. Static and dynamic material characterisation is briefly presented; a detailed discussion on these results may be found in Bonora et al [10]. A preliminary FEM simulation including a simplified model of the material static and dynamic behaviour is performed and compared with the experimental results.

\section{Ballistic tests}

\subsection{Airgun facility}

The ballistic tests have been conducted by means of an airgun facility at the AERMEC - Aeromechanical Structural Systems laboratory of the Aerospace Engineering Department of Politecnico di Torino. The experimental set-up consists of a pressure tank (air filled, maximum operating pressure: 14 bar), a shooting control system, a support structure for targets and a velocity measuring system that allows also to control the trajectory and attitude of flight of the projectile. Some protection shields are located around the impact area as well to stop the bullet after it has hit the target. In fig. 1 an overall functional scheme of the airgun facility is presented. The facility includes a set of barrels of various lengths allowing to adequately cover a wide range of speed until $250 \mathrm{~m} / \mathrm{s}$; barrels' inside diameter is $38,1 \mathrm{~mm}$ (1, 5 inch).

The projectile is made up of a steel cylinder attached on the top of a polyurethane foam cylinder (later on called sabot), the all wrapped with thermo-shrinking packing like shown in fig. 2. The dimensions of the projectile are reported in table 1; the projectile's mass is that of a small turbine blade (engines for executive airplanes). The sabot allows to guide the projectile inside the barrel avoiding 


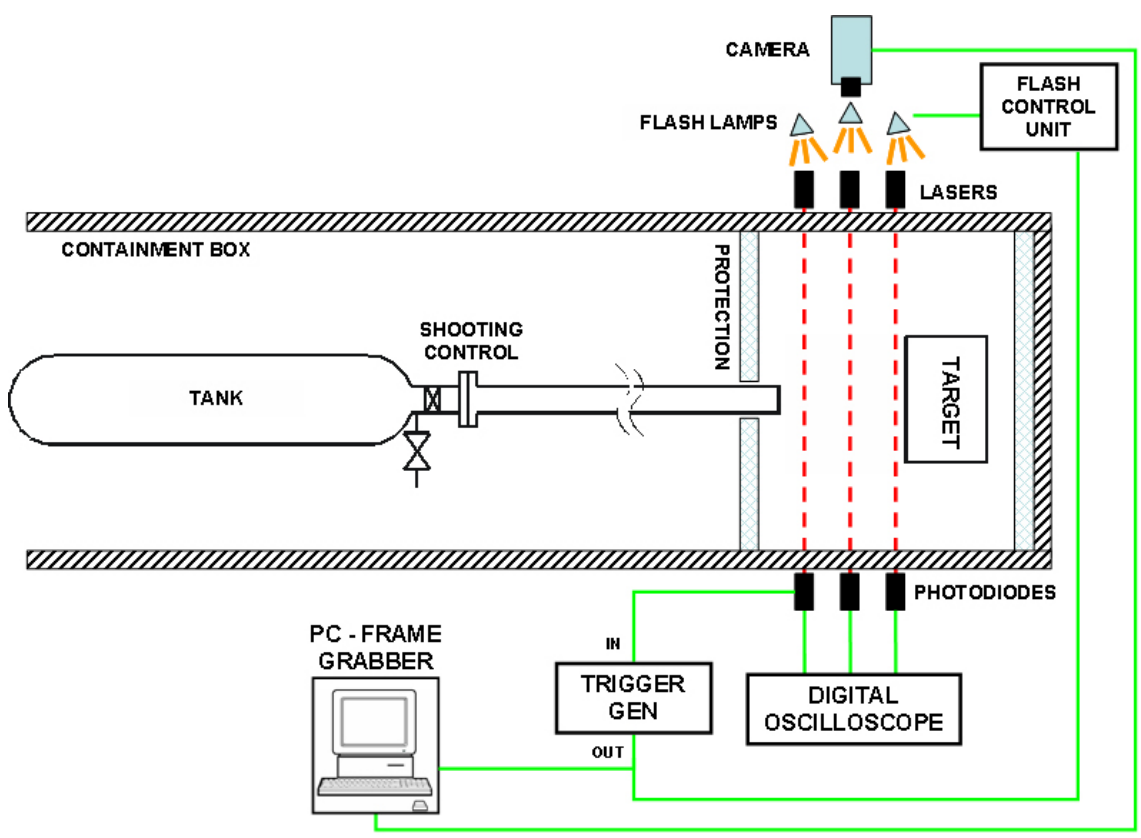

Figure 1: Overall functional scheme of the airgun facility.

rotations and scratches, while the thermo-shrinking packing warrants the projectile integrity and its constant length as well; the last feature is particularly important for a correct measurement of the projectile's velocity before the impact.

The shooting control system is based on a Mylar ${ }^{\circledR}$ membrane that separates the firing section from the pressure tank and barrel; Mylar ${ }^{\circledR}$ membrane is designed to hold out the tank's maximum operating pressure and its burst is induced from an electrical resistance by Joule effect. Two EPDM rubber packings act as electric insulator and as air seal. Both EPDM rubber packings and Mylar ${ }^{\circledR}$ membrane are punching so that they can be inserted in the tightening system as shown in fig. 3 .

Table 1: Projectile's dimensions and masses.

\begin{tabular}{|r|c|c|c|}
\hline & diameter $(\mathrm{mm})$ & length $(\mathrm{mm})$ & mass $(\mathrm{g})$ \\
\hline \hline steel cylinder & 33 & 10 & 67 \\
sabot & 37 & 50 & 5 \\
thermo-shrinking packing & - & - & 4,5 \\
\hline
\end{tabular}

The projectile is inserted into the rear end of the barrel then the diaphragm is inserted in the tightening system which is closed; compressed air is pumped into 

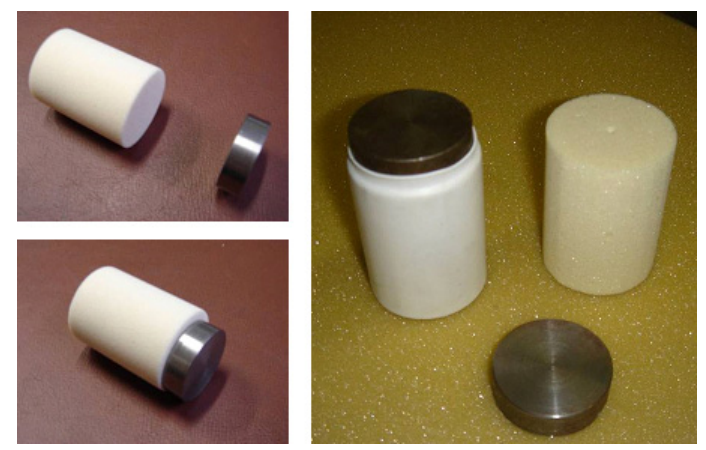

Figure 2: Pictures of projectile made up of a steel cylinder, a polyurethane foam cylinder and a thermo-shrinking packing.

the pressure tank. At firing, the electrical resistance bursts the Mylar ${ }^{\circledR}$ membrane and the projectile is accelerated along the barrel; then it leaves the muzzle and it passes the velocity measurement station before that it impacts the target after about $0,5 \mathrm{~m}$ of free flight.

The target's support structure allows to set the plate with an angle of $60^{\circ}$ between the normal to its surface and the projectile's trajectory, Arace [8]. The plate is simply supported by a rectangular steel frame. Four stoppers are set in the frame's corners to prevent plate's sliding during the impact. Also, the target's support structure is designed to realize an adequate connection with the airgun box so as to transmit the impact forces on the box itself; the high support structure stiffness assures that great part of the strain energy is charged to the panel as well. A picture of target's support structure is shown in fig. 3.

Three laser-light sources on one side of the projectile path and three diode detectors on the other side are used and mounted in lines to match themselves and to measure the projectile's velocity. When the projectile passes between the sources and detectors, laser-light is interrupted and signals are given and stored to a digital oscilloscope: as projectile's length and distances between laser-beams are known, it is possible to estimate both "instantaneous" velocity and average velocity of the projectile just before the impact. The first laser-beam works also as a trigger for the digital high-speed camera system used in the tests. PCO SENSICAM QE digital camera system is used together with three flash-lamps system to control the trajectory and attitude of flight of the projectile both before and while it impacts the target; the airgun box is equipped with two framing windows to allow the highspeed camera to photograph and the flash-lamps to light properly both projectile and target. The system is able to take some snapshots after the projectile leaves the muzzle and while it impacts the target, as shown in fig. 4.

Measurement of velocity is the main feature in experimental ballistic tests. The equipment described above has been purpose-built for this particular application and it was therefore necessary to check it; tests were carried out where projectiles were fired through the impact chamber at different velocities without a target 


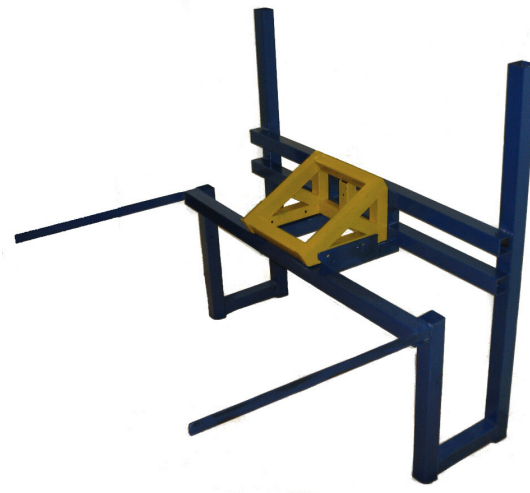

(a)

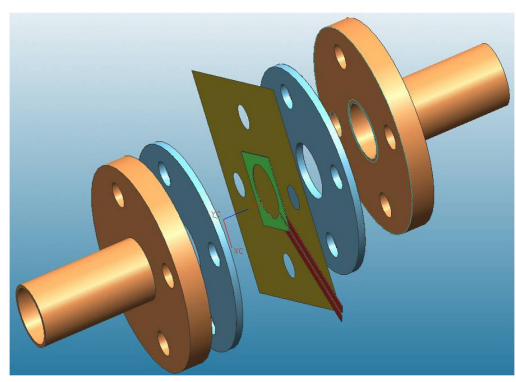

(b)

Figure 3: (a) Picture of target's support structure; (b) Sketch of the shooting control system.
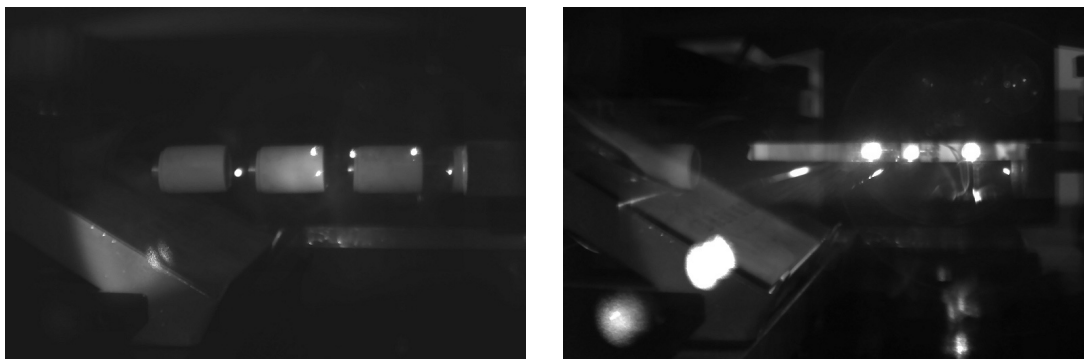

Figure 4: PCO SENSICAM QE digital high-speed camera system. On the left, first frame with four snapshot of the projectile travelling versus the target; on the right, second frame with single snapshot of the impact.

plate. Good agreement was found between the velocity estimated by the laserbeams system and the images obtained from high-speed camera.

\subsection{Experimental results}

At first, a firing tuning process has been done through many preliminary shoot tests that have resulted in a pressure-velocity calibration curve of the system, constantly updated by new tests.

A ballistic campaign has been carried out on four plates of Waspaloy ${ }^{\circledR}$ alloy whose geometric characteristics are indicated in table 2 . All plates are of the same thickness so the experimental goal is to determine a kinetic energy range inside which the limit value resides for the thickness in examination. 
The speed with which to start the ballistic campaign has been evaluated through an energetic method based on an empirical equation obtained for correlation with experimental data, Di Sciuva et al [4]

$$
t=a \cdot\left(E_{k i n}\right)^{b}
$$

where $t$ is the plate's thickness, $a$ and $b$ are obtained by experimental data fitting and $E_{k i n}$ is the kinetic energy of the projectile.

In table 2 are reported all information about several ballistic tests, particularly the projectile's characteristics, the impacts' average speeds, therefore the kinetic energy and the experimental result $(\mathrm{C}=$ containment, $\mathrm{NC}=$ not containment $)$ are pointed out; all values of velocity and kinetic energy are dimensionless because they are confidential company data. In particular, velocities and kinetic energies are divided by the corresponding (containment) limit values.

In figs. 5-6 are shown some photos of the plates \#2 and \#4.

Table 2: Plates' geometric characteristics and ballistic experimental results.

\begin{tabular}{|c|c|c|c|c|c|c|c|}
\hline \multicolumn{4}{|c|}{ Plate } & \multicolumn{4}{c|}{ Projectile } \\
\# & $\mathrm{a}(\mathrm{mm})$ & $\mathrm{b}(\mathrm{mm})$ & $\mathrm{h}(\mathrm{mm})$ & $\mathrm{m}(\mathrm{g})$ & $\tilde{V}$ & $\tilde{E}_{k i n}$ & $\mathrm{C} / \mathrm{NC}$ \\
\hline \hline 1 & 300 & 300 & 1,00 & 76,5 & 1,398 & 1,955 & $\mathrm{NC}$ \\
2 & 300 & 300 & 1,00 & 76,5 & 0,917 & 0,841 & $\mathrm{C}$ \\
3 & 300 & 300 & 1,00 & 76,5 & 1,203 & 1,448 & $\mathrm{NC}$ \\
4 & 299 & 299 & 1,00 & 76,5 & 1,083 & 1,173 & $\mathrm{NC}$ \\
\hline
\end{tabular}

\section{Static characterisation}

Quasi-static tensile tests were carried out according to ASTM standards [11, $12,13]$ to identify the material mechanical properties of the Waspaloy ${ }^{\circledR}$. Seven specimens were used in order to make a proper statistical survey. Both target's plates and specimens were obtained from the same sheet.

The engineering and true mechanical properties for the target are given in table 3; fig. 7 shows the quasi-static tensile engineering stress-strain curve for the target; such information are required in order to calibrate both the analytical model (ref. eqn. 1) and the numerical simulation.

Furthermore, the dynamic response of Waspaloy ${ }^{\circledR}$ at high strain rate has been investigated by means of direct tension Hopkinson pressure bar (DTHPB). Using round bar samples with different reference lengths, the material response in the strain rate range (from $700 \mathrm{~s}^{-1}$ up to $3200 \mathrm{~s}^{-1}$ ) expected to occur under dynamic impact conditions, has been experimentally determined and used to derive the constitutive model to be used in the FEM simulations. 

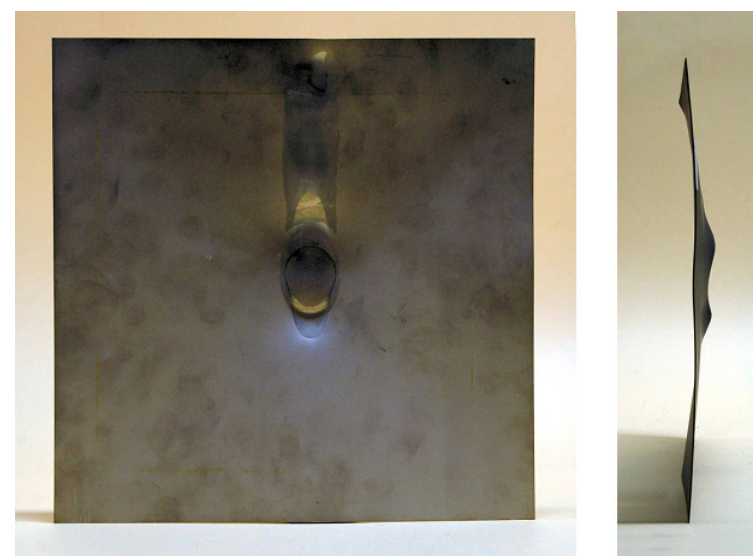

Figure 5: Experimental results: Waspaloy ${ }^{\circledR}$ alloy plate $\# 2,300 \times 300 \times 1,00 \mathrm{~mm}$, $\tilde{E}_{\text {kin }}=0,841$.

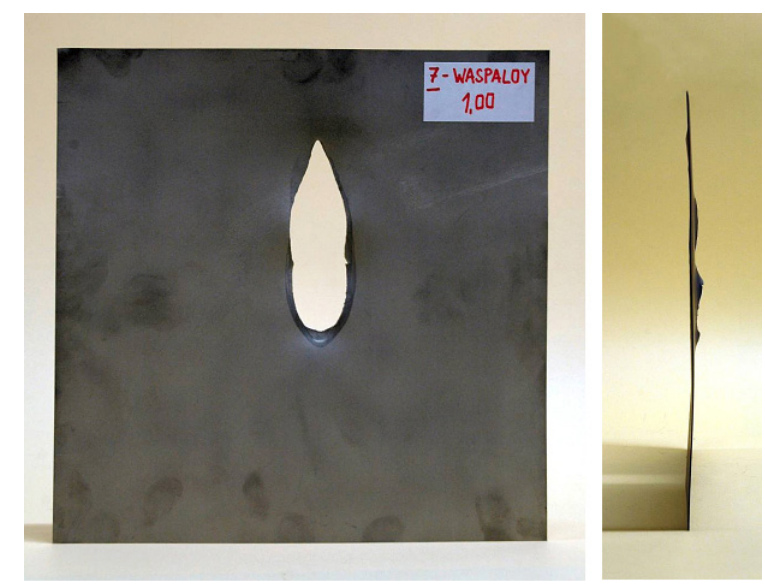

Figure 6: Experimental results: Waspaloy ${ }^{\circledR}$ alloy plate $\# 4,299 \times 299 \times 1,00 \mathrm{~mm}$, $\tilde{E}_{k i n}=1,173$.

\section{Preliminary FEM simulation}

A preliminary estimation of numerical capability to reproduce the experimental ballistic results, using MSC.Dytran ${ }^{\circledR}$, has been done (Degiovanni [14]). A finite element model representative of the true experimental tests has been realized; it is made up of about 270.000 HEXA8 solid elements (with 3 elements in the thickness) and a failure model based on a maximum equivalent plastic strain is used. For these first analyses the material model employed considers in simplified way the mechanical characteristics, both static and dynamic, obtained from the respective tests. 
Table 3: Quasi-static mechanical properties for Waspaloy ${ }^{\circledR}$ alloy.

\begin{tabular}{|l|c|c|c|c|}
\hline & & \multicolumn{2}{|c|}{ Engineering Data } & True Data \\
mean value & $\begin{array}{c}\text { standard } \\
\text { deviation }\end{array}$ & \\
\hline & Unit & & - & - \\
\hline \hline Density & $\left(\mathrm{kg} / \mathrm{m}^{3}\right)$ & 8090 & - & 1590 \\
Tensile ultimate strength & $(\mathrm{MPa})$ & 1264 & 8,8733 & 695 \\
Tensile yield strength & $(\mathrm{MPa})$ & 692 & 12,5884 & 695 \\
Elongation at break & $(\mathrm{mm} / \mathrm{m})$ & 288,85 & 5,239 & 25 \\
Poisson coefficient & & 0,2871 & 0,0119 & - \\
Young Modulus & $(\mathrm{MPa})$ & 226930 & 2423,4 & - \\
\hline
\end{tabular}

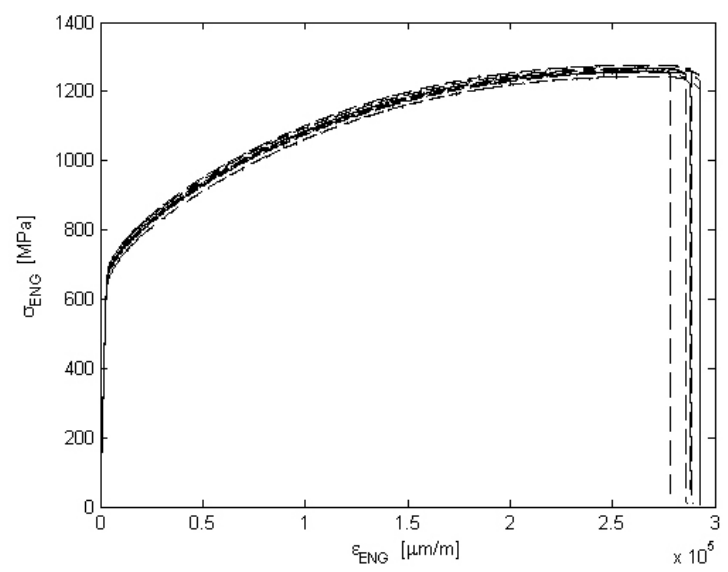

Figure 7: Quasi-static tensile engineering stress-strain curves of Waspaloy ${ }^{\circledR}$ alloy.

Some results are shown in fig. 8 for the velocity of two different projectiles, respectively about experimental limit events of containment and not containment. As preliminary outcomes they show a good agreement with the ballistic tests.

\section{Conclusions}

The design of aircraft engines has also to face containment problems; any object (released blade, disk fragment) impacting the protection case must be contained according to regulations. The evaluation of minimum containment thickness is normally based on simple thickness vs kinetic energy curves; anyway, these curves are obtained through extensive campaigns of experimental tests and numerical simulations. The present article describes some results of a ballistic tests campaign on Waspaloy ${ }^{\circledR}$ alloy plates and some preliminary numerical simulations of the impact experiments; these show that good correlation with tests is obtained (due 


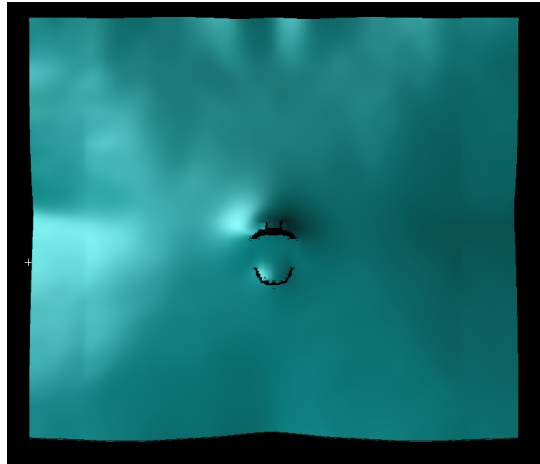

(a) $\tilde{E}_{k i n}=0,841$

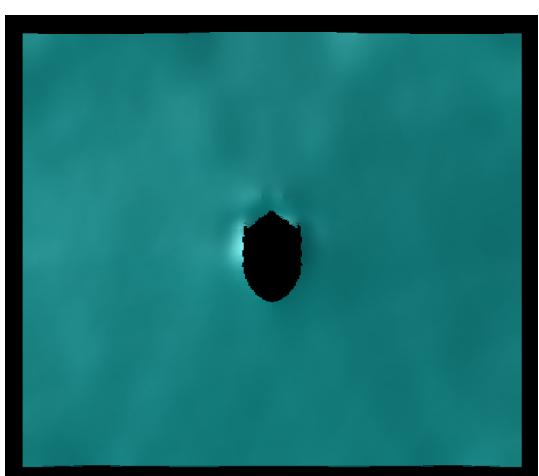

(b) $\tilde{E}_{k i n}=1,173$

Figure 8: Numerical results of preliminary FEM simulation of Waspaloy ${ }^{\circledR}$ containment capacity (MSC.Dytran ${ }^{\circledR}$ ).

to a reliable experimental evaluation of the material mechanical properties, both quasi-static and at high strain rates).

\section{Acknowledgements}

The authors from Politecnico di Torino gratefully acknowledge Messrs Giuseppe Ruvinetti and Lorenzo Mascarello for the helpful and constant technical support during ballistic tests. Also, they acknowledge Regione Piemonte for funding their activity ("Multidisciplinary optimisation of aerospace structural systems", Project E57) in the framework of "Bando Regionale per la Ricerca Scientifica 2004".

The author from Avio S.p.A. acknowledges Dr Antonino Vassallo for his contribution to the activity.

\section{References}

[1] Kelvin Y. N., Turbine Rotor Burst Containment Analysing using Msc/Dytran, Hamilton Standard (United Technologies), Internal Report, 1996.

[2] FAR 33.94 - Blade containment and rotor unbalance tests, Federal Aviation Administration, 1984.

[3] AC 20-128A - Design Considerations for Minimizing Hazards caused by Uncontained Turbine Engine and Auxiliary Power Unit Rotor Failure, Federal Aviation Administration, 1997.

[4] Di Sciuva M., Frola C. \& Salvano S., Low and high velocity impact on Inconel 718 casting plates: ballistic limit and numerical correlation, International Journal of Impact Engineering, 28, pp. 849-876, 2003. 
[5] Carney K., Pereira M., Revilock M. \& Matheny P., Jet engine Fan Blade Containment using Two Alternate Geometries, Proc. of the 4th European LS Dyna Users Conference, Ulm (Germany), 2003.

[6] Sarkar S. \& Atluri S. N., Effects of multiple blade interaction on the containment of blade fragments during a rotor failure, Finite elements in Analysis and Design, 23(2), pp. 211-223, 1996.

[7] Krauss A. \& Frischbier J., Containment and penetration simulation in case of blade loss in a low pressure turbine, MTU Aero Engines GmbH, Internal Report, Monaco, Germany, 2002.

[8] Arace F., Gherlone M. \& Frola C., A simplified methodology for containment case design, Proc. of the XVIII AIDAA National Congress Volterra (Italy), 2005.

[9] Liu D. \& Stronge W.J., Ballistic limit of metal plates struck by blunt deformable missiles: experiments, International Journal of Solids and Structures, 37(10), pp. 1403-1423, 2000.

[10] Bonora N., Ruggiero A., Di Sciuva M., Degiovanni M., Mattone M., Gherlone M. \& Frola C., Nickel base superalloy containment case design: constitutive modeling and computational analysis, to be submitted to Int. J. of Solids and Structures.

[11] ASTM E 8 - Standard Test Methods for Tension Testing of Metallic Materials. ASTM International.

[12] ASTM E 1012 - Standard Practice for Verification of Test Frame and Specimen Alignment Under Tensile and Compressive Axial Force Application. ASTM International.

[13] ASTM E 111 - Standard Test Method for Young's Modulus, Tangent Modulus, and Chord Modulus. ASTM International.

[14] Degiovanni M., Indagine numerico sperimentale di soluzioni strutturali ottimizzate per casing di motori aeronautici, Report DIASP-259, Politecnico di Torino, 2006 